\title{
Emissaries Guide to Worlding:
}

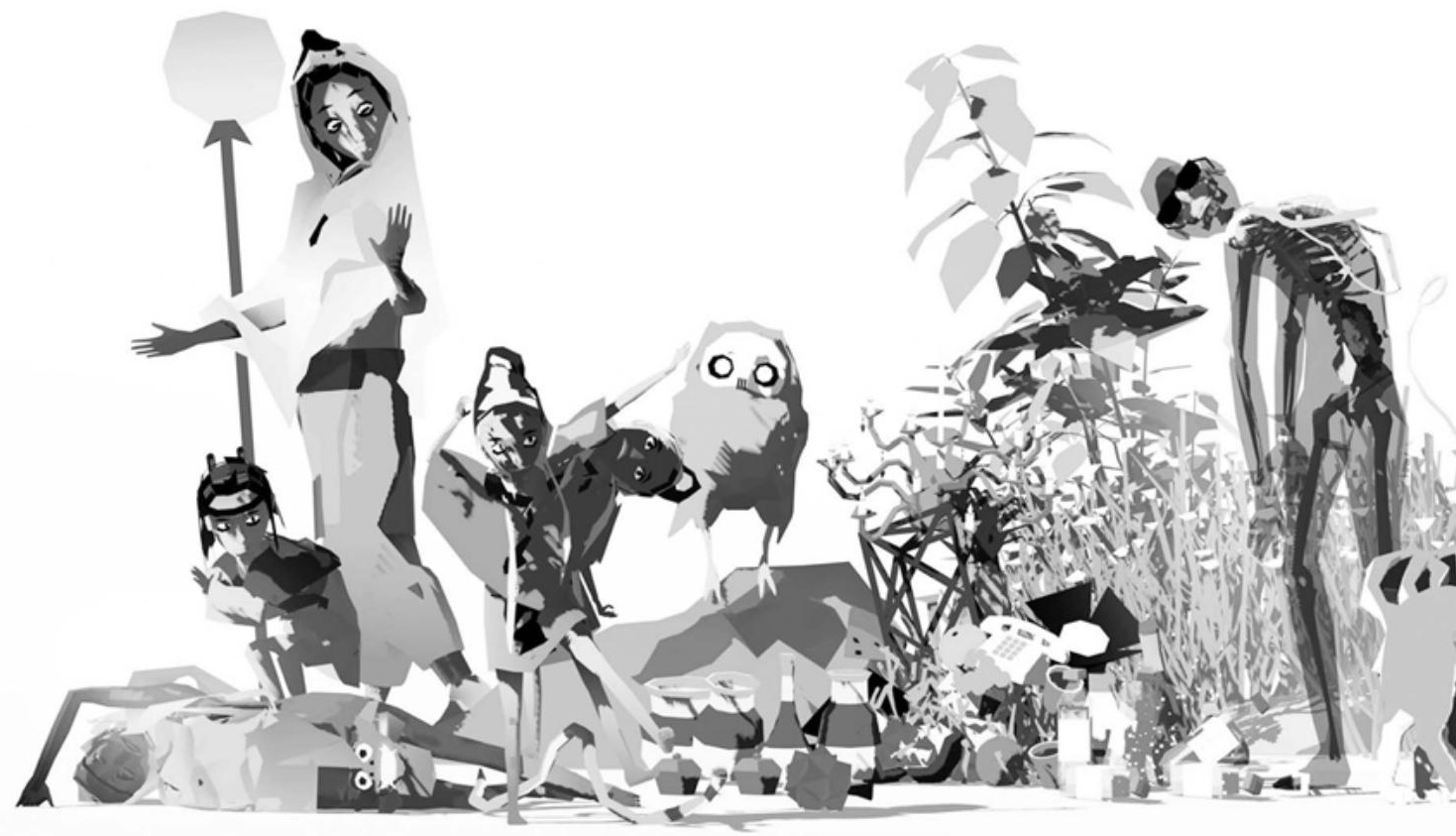


s Emissary, I am responsible for imagining how to display the World so its orientation is narratively clear. So there is a sense of focus and context simultaneously, even though it has no determinate end. I have finally made a World, now I must serve as its most observant documentarian so viewers might have a portal into its activities. What should we look at? Which perspectives are legible? How should we gradually reveal its overwhelming possibility?

I used two virtual cameras in EITSOG: a 'story view' that trailed the Young Ancient, and an 'ecosystem view' to show the entire volcanic environment. With these viewpoints taken together the views would have a sense of both the subjective drama and its place in the context of the drama of the community and the volcano.

I decided to use a panoramic view for EFAP. The virtual camera would track Shiba [Emissary] and her relationship with the human Celebrity, but because of the wideness of the camera's scope, you could see the activity of much of the landscape simultaneously.

I made ESTS a 7:6 square and trained the virtual camera to always focus on the Wormleaf mutation so that it would feel like a kind of ongoing portraiture. The viewer would always be oriented to the life of the mutation, as it evolved from an animated plant to whatever possible life outcome: the subject of Oomen abuse, a vegetative mess, a full-blown monster.

I am responsible for tuning the World so it doesn't wreck itself in two days. There were always strange surprises at the birth of each episode of Emissaries. The Shaman led his community to the edge of the simulation, on the infinity horizon, where he believed it was most safe. Young Ancient walked down into the heart of the volcano when no one listened to her. Seeding fifty members of the ancient community tended to always block Young Emissary from her narrative goals, but twenty members let her succeed too often. Shiba discovering Celebrity at night forked herself hundreds of times due to contagious anxiety. Celebrity failed to decay and outlived everyone by itself. The Oomen reproduced too quickly and eradicated every Wormleaf plant in the ecosystem in one generation. 
The Wormleaves amassed in the centre of the Atoll and created a pit in the terrain that all the Oomen got trapped in. The Oomen children developed a tolerance for eating faeces and subsisted on their own cycle.

Tuning is mainly a matter of tweaking the inter-relationships between agents, like how a reality TV showrunner might tweak its players. Reorganising which of these surprises are generative and which are catastrophic, and amplifying the generative ones, is the harmonising work of tuning.

I am responsible for protecting the World from my own too-human finitude. The temptation to reduce a World into a finite game is to kill the golden goose for quick wins. This is what happened to the housing market in 2008, what happens to every start-up that sees itself merely for its technological function, and what happens to gurus who build a high-walled cult around their own personhood. Many times I faced the temptation to turn Emissaries into a more finite form. The Director in me wanted to export the best run of the simulation and make a 'greatest bits' video. The Hacker wanted to turn it into a video game with points and goals for saving the community, or growing a Wormleaf monster. The Cartoonist wanted to just scrub through run throughs and make an Instagram of the best animated GIFs.

I am responsible for opening up the World to other players. The key quality is that the World has some interface for players to enter into its ongoingness. I exhibited Emissaries in institutions and galleries. I live streamed it. One day the assets of Emissaries, its characters and sub-systems, will be made available to a public. I dream of an Emissaries cognition composer where people can mix and match brain modules and see how the characters come alive differently. And I wish to extend the spirit of Emissaries to those interested in Worlding. Any interface that can produce connection to the World, however significant or niche, is energy and care for the World to keep going. 